J. Lake Sci. (湖泊科学) , 2011, 23(4): 605-611

http: //www. jlakes. org. E-mail : jlakes@niglas.ac.cn

(C) 2011 by Journal of Lake Sciences

\title{
太湖春季浮游植物群落对不同形态氮的吸收"
}

\author{
杨 柳 ${ }^{1,2}$, 章 铭 $^{3}$, 刘正文 ${ }^{1 * *}$ \\ ( 1 : 中国科学院南京地理与湖泊研究所湖泊与环境国家重点实验室,南京 210008) \\ (2:中国科学院研究生院, 北京 100049) \\ (3:华中农业大学水产学院, 武汉 430070)
}

摘 要: 为研究太湖春季浮游植物群落氮吸收特征及其与浮游植物群落结构和环境因子的关系, 于 2010 年 5 月中旬采 集太湖 6 个点位水样, 利用 ${ }^{15} \mathrm{~N}$ 稳定同位素示踪技术, 测定太湖浮游植物群落对硝态氮, 铵态氮和尿素的吸收, 结果表明: 太湖浮游植物群落对铵态氮的吸收速率均值最高, 占几种氮总吸收量 $\rho(\mathrm{DN})$ 的 $62.8 \%$, 各点位值在 $0.181-1.575 \mu \mathrm{mol} /$ $(\mathrm{L} \cdot \mathrm{h})$ 之间. 各点位浮游植物群落对硝态氮和尿素态氮的吸收速率范围分别为 $0.004-0.118 \mu \mathrm{mol} /(\mathrm{L} \cdot \mathrm{h})$ 和 $0.043-$ $1.116 \mu \mathrm{mol} /(\mathrm{L} \cdot \mathrm{h})$. 梅梁湾, 湖心以及五里湖三个湖区浮游植物群落均优先吸收铵态氮、其次为尿素, 对三种氮的吸收速 率都是 $\rho\left(\mathrm{NH}_{4}\right)>\rho(\mathrm{UREA})>\rho\left(\mathrm{NO}_{3}\right)$, 而胥口浮游植物群落优先吸收尿素, 且对尿素的绝对吸收速率最大, 其次为铵态 氮, 硝态氮最低. 在可利用氮含量较高的情况下, 浮游植物丰度、组成结构等因子可能是影响太湖浮游植物群落氮吸收空 间差异的最重要因素.

关键词: 太湖;浮游植物; ${ }^{15} \mathrm{~N}$ 示踪技术; 氮吸收; 尿素

\section{Uptake of various forms of nitrogen by phytoplankton community in spring in Lake Taihu}

YANG Liu $^{1,2}$, ZHANG Ming ${ }^{3} \&$ LIU Zhengwen ${ }^{1}$

(1: State Key Laboratory of Lake Science and Environments, Nanjing Institute of Geography and Limnology, Chinese Academy of Sciences, Nanjing 210008, P. R. China)

(2: Graduate University of Chinese Academy of Sciences, Beijing 100049, P. R. China)

(3: College of Fisheries, Huazhong Agricultural University, Wuhan 430070, P. R. China)

Abstract: To characterize the nitrogen uptake by phytoplankton and its relationships with phytoplankton community structure and enviromental factors, we measureed the uptake of ammonium, nitrate and urea by phytoplankton community from different areas of Lake Taihu in mid-May, 2010, using the ${ }^{15} \mathrm{~N}$-tracer technology. The results showed that: Uptake rate of ammonium was highest for all lake areas, accounting for $62.8 \%$ of the total nitrogen uptake. The uptake rates were $0.181-1.575,0.004-0.118$ and $0.043-1.116 \mu \mathrm{mol} /(\mathrm{L} \cdot \mathrm{h})$ for ammonium, nitrate and urea, respectively. Phytoplankton communities preferred uptaking ammonium in Meiliang Bay, Lake Center and Wuli Bay and the uptake rates of the three forms of nitrogen were arranged as follows: $\rho\left(\mathrm{NH}_{4}\right)>$ $\rho$ (UREA $)>\rho\left(\mathrm{NO}_{3}\right)$. However, phytoplankton community in Xukou Bay preferred urea to ammonium and the uptake rate of urea was the highest, the uptake rate of nitrate was the lowest. When concentrations of nitrogen are high, phytoplankton abundance and community structure are likely important factors determining the nitrogen uptake by phytoplankton community in Lake Taihu.

Keywords: Lake Taihu; phytoplankton; ${ }^{15} \mathrm{~N}$-tracer technique; nitrogen uptake; urea

浮游植物是湖泊生态系统中的重要初级生产者, 而氮、磷是影响浮游植物生长的重要环境因子 ${ }^{[1]}$. 许海 等研究表明,太湖中氮对浮游植物生长的限制作用不可忽视, 甚至有时会超过磷的作用 ${ }^{[2]}$.一般认为, 溶解

* 科技部支撑计划项目 (2007BAC26B02)、国家 “973” 计划项目 (2008CB418104) 和国家自然科学基金项目 (31070419) 联合资助. 2010-11-03 收稿;2010-11-19 收修改稿. 杨柳,女,1985 年生, 硕士研究生; E-mail: ylniglas@163.com.

** 通讯作者; E-mail: zliu@ niglas. ac. cn. 
性无机氮是浮游植物吸收氮的主要形式. 也有大量研究表明,浮游植物也可以吸收尿素、溶解游离氨基酸等 小分子有机氮 ${ }^{[3-4]}$, 但对不同形态氮的吸收因浮游植物群落组成和环境条件的不同而存在差异 ${ }^{[5]}$. 浮游植物 对氮的吸收, 是湖泊生态系统氮循环的一个重要环节. 国外对湖泊浮游植物氮吸收的相关研究很多 ${ }^{[4,6-10]}$, 而国内的相关研究很少 ${ }^{[11-13]}$,太湖尚无相关报道.

太湖面积 $2338 \mathrm{~km}^{2}$, 平均水深 $1.9 \mathrm{~m}$, 是中国第三大淡水湖泊 ${ }^{[14]}$. 太湖不同湖区水质状况差别较大, 梅梁湾 湖区受人湖河流污染较严重, 富营养化程度高, 蓝藻水华频频暴发. 湖心区受外源污染较轻, 风浪扰动强烈. 五 里湖区相对封闭, 较其他湖区风浪小. 胥口湾湖区污染较轻, 水草相对丰富, 水质较好. 本文以上述湖区为对 象, 利用 ${ }^{15} \mathrm{~N}$ 稳定同位素示踪技术, 测定浮游植物群落对硝态氮、铵态氮和尿素态氮的吸收, 探讨太湖浮游植物 群落结构和环境条件对浮游植物氮吸收的影响,并为太湖生态系统氮循环研究提供一些基础数据.

\section{1 材料与方法}

\section{1 采样}

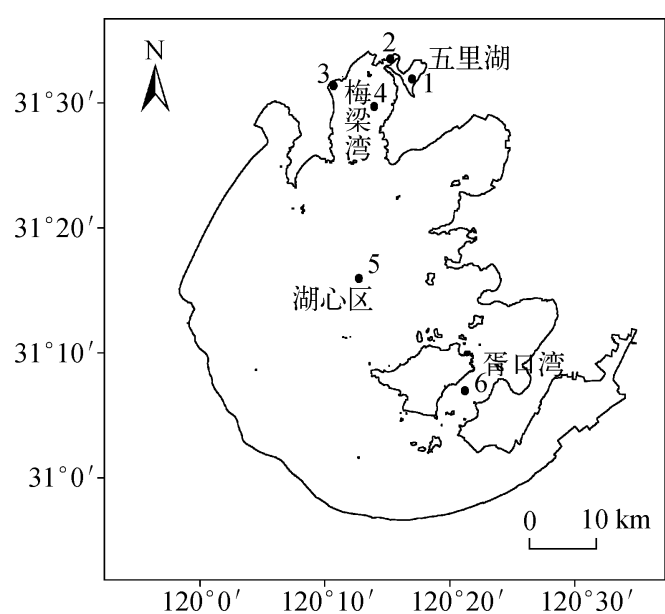

图 1 太湖采样点分布

Fig. 1 The location of sampling stations in Lake Taihu

本研究共设 6 个采样点 (图 1 ), 其中 1 号点位于 五里湖, $2-4$ 号点位于梅梁湾、5 号点位于湖心、6 号 点位于胥口湾. 采样于 2010 年 5 月 $16 、 17$ 日进行, 用 采水器采水面下约 $30 \mathrm{~cm}$ 深的水样 $5 \mathrm{~L}$, 装人塑料水壸 中, 用于测定水化指标和浮游植物氮吸收. 另采 $1 \mathrm{~L}$ 水样,加 $10 \mathrm{ml}$ 鲁哥试剂固定, 用于浮游植物群落组 成分析. 采样的同时, 用 YSI6600V2 型多参数水质监 测仪 (美国) 测定采样水深处的温度 ( T) 、 $\mathrm{pH}$ 值、浊 度 (Turbidity)、溶解氧 (DO) 等指标、用透明度盘测定 透明度 (SD). 测定氮吸收的浮游植物用孔径为 $180 \mu \mathrm{m}$ 的绢网滤除大型浮游动物和碎屑, 以排除对 氮吸收的干扰.

\section{2 水化指标测定}

采用过硫酸盐氧化法测定水中总氮 $(\mathrm{TN})$ 、总磷 (TP), 水样用孔径为 $0.45 \mu \mathrm{m}$ 的醋酸纤维膜过滤后, 膜用于叶绿素测定, 水样用于总溶解态氮 (TDN)、总 溶解态磷 $(\mathrm{TDP})$ 、铵氮 $\left(\mathrm{NH}_{4}-\mathrm{N}\right)$ 、硝态氮 $\left(\mathrm{NO}_{3}-\mathrm{N}\right)$ 、尿 素态氮 $($ Urea- $-\mathrm{N})$ 、亚硝态氮 $\left(\mathrm{NO}_{2}-\mathrm{N}\right)$ 、溶解性正磷酸盐 $\left(\mathrm{PO}_{4}-\mathrm{P}\right)$ 测定, 其中 TDN、TDP 测定采用过硫酸盐氧化 法 $^{[15]}$, 尿素测定采用二乙酰一肜法 ${ }^{[16]}, \mathrm{NH}_{4}-\mathrm{N} 、 \mathrm{NO}_{3}-\mathrm{N} 、 \mathrm{NO}_{2}-\mathrm{N} 、 \mathrm{PO}_{4}-\mathrm{P}$ 测定采用微量流动注射分析系统 (Skalar-SA1000). 初级生产力采用现场模拟法, 在梅梁湾岸边水池中挂黑白瓶, 对初始状态的溶解氧和二十 四小时后的黑瓶、白瓶溶解氧进行测定, 从而计算净初级生产力和毛初级生产力.

\section{3 浮游植物分析}

浮游植物计数采用计数框行格法, 一般计数 30 个视野, 使得计数值在 300 个以上. 同时对异形胞进行计 数; 藻类生物体积根据各藻类相近几何形状的体积公式计算; 假定浮游植物藻类的密度为 $1 \mathrm{~g} / \mathrm{cm}^{3}$, 计算出浮 游植物生物量 ${ }^{[17]}$. 浮游植物种类鉴定参照《中国淡水藻类: 系统、分类及生态》 ${ }^{[18]}$. 相对丰度即某种 (属) 丰 度占总丰度的百分比大于 $15 \%$ 的定为优势种 (属).

\section{4 氮吸收实验}

太湖不同湖区浮游植物对不同形态氮吸收 速率测定采用挂瓶的方法, 将 $250 \mathrm{ml}$ 的透明聚乙 烯培养瓶分别加人各样点水样 $200 \mathrm{ml}$, 再加人三 种不同形态的氮稳定同位素示踪剂 (表 1), 每个

表 1 示踪剂添加浓度

Tab. 1 The concentrations of ${ }^{15} \mathrm{~N}$-tracers

\begin{tabular}{lccc}
\hline 示踪剂 & $\begin{array}{c}\text { 添加后浓度 } \\
(\mu \mathrm{mol} / \mathrm{L})\end{array}$ & $\begin{array}{c}\text { 加人母液体积 } \\
(\mathrm{ml})\end{array}$ & $\begin{array}{c}\text { 母液浓度 } \\
(\mu \mathrm{mol} / \mathrm{L})\end{array}$ \\
\hline${ }^{15} \mathrm{NH}_{4} \mathrm{Cl}$ & 0.099 & 0.02 & 987 \\
${ }^{15} \mathrm{NaNO}_{3}$ & 0.252 & 0.05 & 1009 \\
${ }^{15} \mathrm{Urea}$ & 0.098 & 0.02 & 980 \\
\hline
\end{tabular}


样点每种形态氮设置两个重复. 另外, 每个点位水样挂两个不添加同位素的空白瓶用来测定浮游植物的氮 同位素自然丰度. 添加的同位素浓度要小于或等于底物浓度的 $10 \%{ }^{[19]}$. 将培养瓶挂于距水面 $30 \mathrm{~cm}$ 处, $2 \mathrm{~h}$ 后 往瓶中加人饱和氯化锌溶液终止实验. 带回实验室, 用预先在 $450^{\circ} \mathrm{C}$ 马弗炉中处理 $3 \mathrm{~h}$ 的 $\mathrm{GF} / \mathrm{C}$ 膜过滤, 再过 滤 $5 \mathrm{ml}$ 去离子水以清洗掉吸附在滤膜上的示踪剂. 过滤后的膜放人 $70^{\circ} \mathrm{C}$ 的烘箱中, $48 \mathrm{~h}$ 后称重. 最后用刀片 刮下浮游植物, 研磨成粉末,用同位素质谱仪 (MAT-251 型) 测定同位素比值.

根据太湖站 2008 及 2009 年 5 月份数据和预实验测定的梅梁湾尿素数据发现, 铵态氮, 硝态氮及尿素态 氮浓度均远大于 $1 \mu \mathrm{g} / \mathrm{L}$, 不需要利用米氏方程进行修正 ${ }^{[19]}$, 因此, 此次未进行吸收动力学测定.

参照如下公式, 计算相对吸收速率 $V\left(\mathrm{~h}^{-1}\right)$, 绝对吸收速率 $\rho(\mu \mathrm{mol} /(\mathrm{L} \cdot \mathrm{h}))$ 以及相对优先指 数 $R P I^{[12,19]}$.

$$
V=\frac{{ }^{15} N_{\mathrm{s}}-{ }^{15} N_{\mathrm{n}}}{\left({ }^{15} N_{\mathrm{enr}}-{ }^{15} N_{\mathrm{n}}\right) T}
$$

式中, ${ }^{15} N_{\mathrm{s}}$ 为实测样品的 ${ }^{15} \mathrm{~N}$ 丰度, ${ }^{15} N_{\mathrm{n}}$ 为浮游植物 ${ }^{15} \mathrm{~N}$ 的天然丰度, ${ }^{15} N_{\text {enr }}$ 为加人示踪剂后培养介质初始 ${ }^{15} \mathrm{~N}$ 丰度, $T$ 为培养时间 $(\mathrm{h})$.

$$
\rho=V \times P N
$$

式中, $P N$ 为实测样品的颗粒态氮含量 $(\mu \mathrm{mol} / \mathrm{L})$, 通过同位素质谱仪测定.

$$
R P I\left(\frac{N H_{4}}{D N}\right)=\frac{\rho\left(N H_{4}\right)}{\rho(D N)} / \frac{\left[N H_{4}\right]}{[D N]}
$$

式中, $\rho\left(\mathrm{NH}_{4}\right)$ 为浮游植物群落对铵态氮的绝对吸收速率, $\rho(\mathrm{DN})$ 为浮游植物群落对铵态氮、硝态氮、尿素态 氮绝对吸收速率之和, $\left[\mathrm{NH}_{4}\right]$ 为培养介质中铵态氮的浓度, $[\mathrm{DN}]$ 为培养介质中铵态氮、硝态氮、尿素态浓度 之和, $R P I\left(\mathrm{NO}_{3} / \mathrm{DN}\right) 、 R P I(\mathrm{UREA} / \mathrm{DN})$ 计算公式与 $R P I\left(\mathrm{NH}_{4} / \mathrm{DN}\right)$ 类似.

\section{2 结果}

\section{1 理化指标}

6 个研究样点的水温差别不大, $\mathrm{pH}$ 值在 $7.95-9.07$ 之间, 溶解氧范围为 $8.66-9.52 \mathrm{mg} / \mathrm{L}$, 浊度在 $23.4-$ $91.6 \mathrm{NTU}$ 之间, 透明度最大值为 $40 \mathrm{~cm}$, 出现在 1 号点五里湖, 3 和 4 号点梅梁湾最低, 为 $25 \mathrm{~cm}$. 各湖区营养状 况差别很大: 位于梅梁湾和湖心区的 $2 、 3 、 4 、 5$ 号点 TP 浓度均较高, 最高值在 3 号点, 为 $0.114 \mathrm{mg} / \mathrm{L}$, 位于胥 口湾的 6 号点的总磷浓度最低, 为 $0.063 \mathrm{mg} / \mathrm{L}$. 梅梁湾、湖心区的 $\mathrm{TN}$ 浓度均大于 $4.00 \mathrm{mg} / \mathrm{L}$. 位于五里湖的 1 号点总氮浓度最低, 为 $1.2 \mathrm{mg} / \mathrm{L}$. 硝态氮、铵态氮、尿素态氮以及氮磷比的最低值也都出现在五里湖, 尤其是 硝态氮只有 $0.351 \mathrm{mg} / \mathrm{L}$, 明显低于其他几个样点, 其次为胥口湾, 而梅梁湾湖区的硝态氮含量则很高, 普遍在 $2.8 \mathrm{mg} / \mathrm{L}$ 以上. 与营养盐规律相反, 五里湖点位的叶绿素 a 含量明显高于其它点位 (表 2). 五里湖样点无论 毛生产力还是净生产力都最高, 其值是最低值 (湖心区) 的 4 倍左右 (图 2a).

\section{2 浮游植物群落组成}

本文共记录到浮游植物 6 门 42 种, 主要有蓝藻门、硅藻门、隐藻门、绿藻门. 优势属有小环藻 (Cyclotel$l a) 、$ 蓝隐藻 (Chroomonas)、席藻 (Phormidium)、鱼腥藻 (Anabaena)、平裂藻 (Merismopedia) 等. 小环藻在各湖 区均占优势, 蓝藻门中的席藻在梅梁湾和五里湖、湖心区所占比例也较大. 湖心区的优势属还有鱼腥藻和平 裂藻. 隐藻在胥口湾浮游植物群落中占优势 (表 3 ). 各样点浮游植物丰度范围为 $4.13 \times 10^{6}-3.02 \times 10^{7}$ cells/ $\mathrm{L}$, 梅梁湾湖区的 $2 、 4$ 号点最高, 其次为五里湖, 而胥口湾最低. 浮游植物生物量范围为 $1.3-17.6 \mathrm{mg} / \mathrm{L}$, 五里 湖最高, 胥口湾最低. 虽然除了 1 号点, 均检测出固氮藻, 但除 5 号样点出现少量异形胞 (相对丰度为 $0.04 \%$ ) 外,其余样点均未检测到异形胞.

\section{3 氮吸收特征}

总体来看, 太湖浮游植物群落对三种形态氮吸收的吸收速率存在显著差异 $(P<0.05)$, 其中对铵态氮的 吸收速率均值最高, 为 $0.75 \mu \mathrm{mol} /(\mathrm{L} \cdot \mathrm{h})$, 各点位值在 $0.181-1.575 \mu \mathrm{mol} /(\mathrm{L} \cdot \mathrm{h})$ 之间, 对硝态氮的平均吸 收速率为 $0.034 \mu \mathrm{mol} /(\mathrm{L} \cdot \mathrm{h})$, 各点位值在 $0.004-0.118 \mu \mathrm{mol} /(\mathrm{L} \cdot \mathrm{h})$ 之间, 对尿素态氮的平均吸收速率 
表 2 太湖各样点理化指标

Tab. 2 Physicochemical parameters of the six study stations in Lake Taihu

\begin{tabular}{ccccccc}
\hline 参数 & 1 号点 & 2 号点 & 3 号点 & 4 号点 & 5 号点 & 6 号点 \\
\hline $\mathrm{T}\left({ }^{\circ} \mathrm{C}\right)$ & 20.33 & 19.83 & 19.82 & 19.26 & 18.26 & 19.43 \\
$\mathrm{pH}$ & 9.07 & 8.66 & 8.73 & 8.86 & 7.95 & 7.95 \\
浊度 $(\mathrm{NTU})$ & 23.4 & 27.5 & 91.6 & 76 & 65.3 & 76.3 \\
$\mathrm{DO}(\mathrm{mg} / \mathrm{L})$ & 9.52 & 8.66 & 8.7 & 9.02 & 9.03 & 9.02 \\
$\mathrm{SD}(\mathrm{cm})$ & 40 & 35 & 25 & 25 & 30 & 30 \\
$\mathrm{TN}(\mathrm{mg} / \mathrm{L})$ & 1.20 & 4.28 & 4.23 & 4.05 & 0.11 & 3.40 \\
$\mathrm{TP}(\mathrm{mg} / \mathrm{L})$ & 0.073 & 0.095 & 0.114 & 0.084 & 0.083 & 0.063 \\
$\mathrm{TN}: \mathrm{TP}$ & 16.5 & 44.83 & 37.21 & 48.13 & 49.32 & 53.82 \\
$\mathrm{PO}-\mathrm{P}(\mathrm{mg} / \mathrm{L})$ & 0.001 & 0.004 & 0.018 & 0.006 & 0.002 & 0.001 \\
$\mathrm{NO}_{2}-\mathrm{N}(\mathrm{mg} / \mathrm{L})$ & 0.008 & 0.029 & 0.054 & 0.012 & 0.012 & 0.007 \\
$\mathrm{NO}_{3}-\mathrm{N}(\mathrm{mg} / \mathrm{L})$ & 0.351 & 2.935 & 2.982 & 3.053 & 2.379 & 2.178 \\
$\mathrm{NH}_{4}-\mathrm{N}(\mathrm{mg} / \mathrm{L})$ & 0.043 & 0.059 & 0.095 & 0.047 & 0.083 & 0.053 \\
$\mathrm{Urea}_{\mathrm{r}} \mathrm{N}(\mathrm{mg} / \mathrm{L})$ & 0.038 & 0.141 & 0.184 & 0.101 & 0.091 & 0.048 \\
$\mathrm{Chl}_{.} \mathrm{a}(\mu \mathrm{g} / \mathrm{L})$ & 37.42 & 28.22 & 16.61 & 20.25 & 15.85 & 15.46 \\
\hline
\end{tabular}
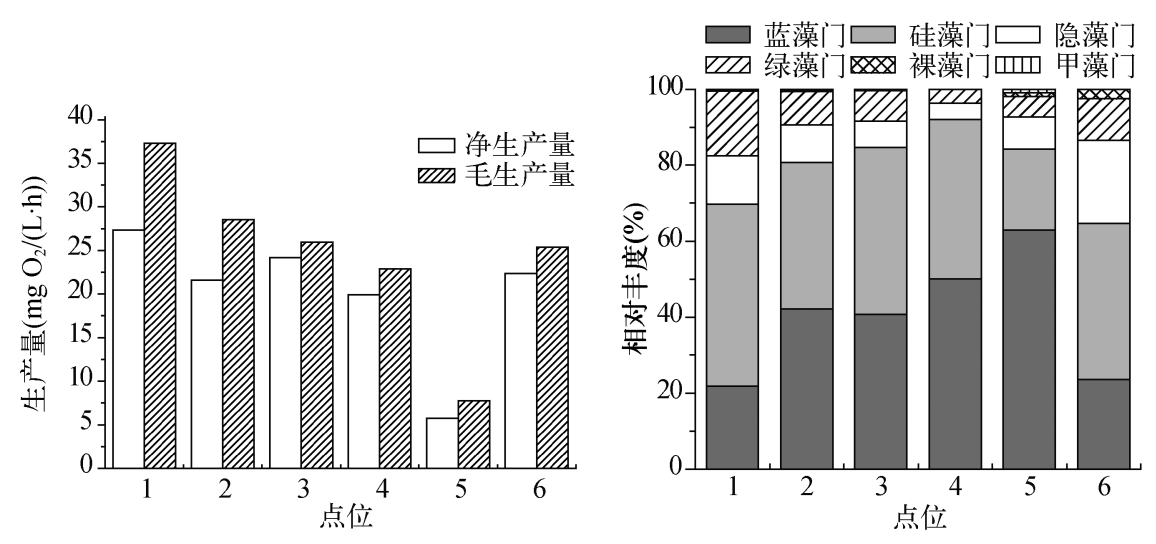

图 2 太湖各点位浮游植物初级生产力和群落结构组成

Fig. 2 Phytoplankton primary production(a) and community composition(b) of the six sites in Lake Taihu

表 3 太湖各点位浮游植物优势属及相对丰度 (\%)

Tab. 3 Dominant phytoplankton genera and relative abundance of the six sites in Lake Taihu

\begin{tabular}{ccccccc}
\hline 属名 & 1 号点 & 2 号点 & 3 号点 & 4 号点 & 5 号点 & 6 号点 \\
\hline 小环藻 & 45.09 & 37.54 & 42.49 & 40.62 & 20.11 & 33.37 \\
席藻 & 19.63 & 38.25 & 39.19 & 28.92 & 25.06 & 23.96 \\
蓝隐藻 & 5.84 & 8.07 & 5.49 & 3.08 & 5.93 & 14.55 \\
鱼腥藻 & 0 & 1.05 & 0.73 & 11.38 & 13.79 & 0 \\
平裂藻 & 0 & 0 & 0 & 9.85 & 21.10 & 0 \\
\hline
\end{tabular}


为 $0.41 \mu \mathrm{mol} /(\mathrm{L} \cdot \mathrm{h})$, 各点位值在 $0.043-1.116 \mu \mathrm{mol} /(\mathrm{L} \cdot \mathrm{h})$ 之间 $($ 表 4$)$. 各点位浮游植物群落对铵态氮、 硝态氮、尿素态氮的吸收速率之和 $\rho(\mathrm{DN})$ 大小依次为: $1>2>6>5>4>3$. 梅梁湾, 湖心以及五里湖三个湖 区浮游植物对三种氮的吸收速率都是 $\rho\left(\mathrm{NH}_{4}\right)>\rho(\mathrm{UREA})>\rho\left(\mathrm{NO}_{3}\right)$, 而胥口湾浮游植物群落对尿素态氮的 绝对吸收速率最大, 其次为铵态氮, 硝态氮最低.

太湖浮游植物群落对铵态氮、硝态氮 和尿素态氮的相对优先指数分别为 $25.45 、 0.03$ 和 $13.24 .1 、 2 、 3 、 4 、 5$ 号点位 的氮吸收相对优先指数均是铵态氮 $>$ 尿 素 > 硝态氮, 6 号点对尿素的相对优先指 数最大, 其次为铵态氮, 硝态氮的最低 (表 5 ).

\section{3 讨论}

\section{1 太湖浮游植物群落对不同形态氮吸 收的比较}

太湖浮游植物群落对不同形态氮的 吸收速率存在显著差异 $(P<0.05)$. 从太 湖总体情况来看, 浮游植物对铵态氮的吸 收速率最大, 其次为尿素态氮, 而对硝态 氮的吸收速率最小. Présing 等对匈牙利西 部的富营养湖泊巴拉顿湖的浮游植物群 落对三种形态氮吸收进行了研究, 其结论 与本研究结论相似 ${ }^{[9]}$. 虽然本文各采样点 铵态氮的浓度均远小于硝态氮, 但对铵态 氮的吸收占三种氮总吸收量 $\rho(\mathrm{DN})$ 的 $62.8 \%$. 一般认为, 铵态氮是浮游植物最 喜好的氮形态, 因为与其他形态氮相比, 吸收铵态氮所消耗的能量最少. $\mathrm{Gu}$ 等对 Okeechobee 湖的研究也发现浮游植物对 铵态氮的吸收占主导, 达到 $53 \%{ }^{[10]}$. 由此
表 4 太湖各点位浮游植物群落对不同形态氮 的吸收速率 $(\mu \mathrm{mol} /(\mathrm{L} \cdot \mathrm{h}))$

Tab. 4 Uptake rates for ammonium, nitrate, urea by phytoplankton communities of the six sites in Lake Taihu

\begin{tabular}{cclcc}
\hline 点位 & $\rho\left(\mathrm{NH}_{4}\right)$ & $\rho\left(\mathrm{NO}_{3}\right)$ & $\rho(\mathrm{UREA})$ & $\rho(\mathrm{DN})$ \\
\hline 1 & 1.575 & 0.118 & 0.505 & 2.198 \\
2 & 1.024 & 0.02 & 0.444 & 1.488 \\
3 & 0.181 & 0.004 & 0.043 & 0.228 \\
4 & 0.505 & 0.009 & 0.177 & 0.691 \\
5 & 0.979 & 0.021 & 0.175 & 1.175 \\
6 & 0.237 & 0.033 & 1.116 & 1.386 \\
平均值 & 0.750 & 0.034 & 0.410 & 1.194 \\
\hline
\end{tabular}

表 5 太湖各点位浮游植物氮吸收的相对优先指数

Tab. 5 The relative preference indices of phytoplankton communities to nitrogen of the six sites

\begin{tabular}{cccc}
\hline 点位 & $R P I\left(\mathrm{NH}_{4} / \mathrm{DN}\right)$ & $R P I\left(\mathrm{NO}_{3} / \mathrm{DN}\right)$ & $R P I(\mathrm{UREA} / \mathrm{DN})$ \\
\hline 1 & 6.96 & 0.06 & 3.77 \\
2 & 36.21 & 0.01 & 7.16 \\
3 & 27.24 & 0.02 & 3.53 \\
4 & 49.39 & 0.01 & 9.14 \\
5 & 25.60 & 0.02 & 4.78 \\
6 & 7.30 & 0.03 & 51.05 \\
平均值 & 25.45 & 0.03 & 13.24 \\
\hline
\end{tabular}
可见, 在太湖这种铵态氮对浮游植物吸收贡献最大的情况下, 控制铵态氮的输人是很重要的. 众所周知, 水 体富营养化是由氮、磷的增多导致的,但目前对太湖氮的研究, 只局限在硝态氮、铵态氮等溶解态无机氮. 然 而早在 1970s 国外就有研究对湖泊中尿素含量进行调查 ${ }^{[5]}$. 相关研究表明赤潮与尿素密切相关 ${ }^{[20]}$. 本研究 表明太湖中的尿素含量也不容忽视,其最高浓度达到 $0.184 \mathrm{mg} / \mathrm{L}$ (3 号点). 中国是个农业大国,化肥施用量 大, 且流失率高, 大量化肥随径流进入湖泊. 同时, 湖水中鱼类和浮游动物也会排泄释放尿素 ${ }^{[21]}$. 很多研究都 表明, 浮游植物不仅能够吸收尿素, 且对其吸收速率大于硝态氮, 甚至出现大于铵态氮的情况 ${ }^{[9,20,22]}$. 本研究 也发现, 太湖浮游植物群落对尿素态氮的吸收速率平均值是硝态氮的 10 倍之多. 位于胥口湾点位的浮游植 物群落对尿素态氮的吸收速率甚至超过对铵态氮的吸收速率. 太湖近些年蓝藻水华的加剧是否与尿素含量 有关值得进一步研究.

\section{2 环境因子及浮游植物群落组成对浮游植物氮吸收的影响}

浮游植物对氮的吸收与浮游植物群落结构 (包括浮游植物丰度、组成) 等密切相关. 同时可能也受采样 点原有环境因子, 尤其是营养盐浓度的影响. 进一步分析显示, 浮游植物对硝态氮的吸收速率与硝态氮的浓 度呈显著负相关 $(r=-0.98, P=0.0001)$, 对铵态氮的吸收速率与浮游植物丰度呈正相关 $(r=0.84, P=$ $0.017)$. 浮游植物对尿素的吸收比较复杂, 与浮游植物丰度及尿素浓度均无显著相关性. 
从各个湖区来看, 五里湖浮游植物群落氮吸收速率最高, 这可能是由于五里湖较为封闭, 虽然营养盐浓 度不是很高, 但浮游植物丰度和初级生产力都是几个点位中最高的, 因此浮游植物群落氮吸收速率也相应 较大. 梅梁湾湖区几个点位水体氮、磷浓度均较高, 但浮游植物对氮的吸收速率存在较大差异. 2 号点虽然 氮、磷浓度较高, 浮游植物丰度和初级生产力等指标都与五里湖接近, 此点位浮游植物群落对氮吸收速率仅 次于五里湖. 梅梁湾的 $3 、 4$ 号点, 虽然硝态氮、铵态氮、尿素浓度均较高, 但浮游植物丰度和初级生产力都低 于五里湖, 其群落氮吸收速率显著低于五里湖 $(P<0.05)$. 可能由于浮游植物群落长期处于氮营养盐充足的 状态下, 导致其对氮营养盐的需求不高. 6 号点浮游植物丰度很低, 而且各种营养盐的含量也不高, 但此点位 浮游植物群落对尿素的吸收速率较高, 可能也与其群落结构有关. 不同种类浮游植物对不同氮的吸收速率 有很大差异 ${ }^{[23-24]}$. 本研究 6 号点不同于其他点, 隐藻在浮游植物总丰度中所占比例较大 (图 3 ). 有可能与其 他形态氮相比, 鞭毛藻能够更好地吸收尿素态氮 ${ }^{[24]}$, 但目前尚无关于隐藻氮吸收的相关报道, 有待进一步研 究. 由此可见, 在可利用氮含量较高的情况下, 浮游植物丰度、组成是影响太湖浮游植物群落氮吸收空间差 异的最主要因素.

致谢: 吕志军、李珂、姚思鹏、周德勇、刘旭博、于谨磊、何虎等协助完成采样工作, 蔡永久为本文提出了宝贵 的修改意见,在此对他们表示衷心的感谢.

\section{4 参考文献}

[ 1 ] Hecky RE, Kilham P. Nutrient limitation of phytoplankton in freshwater and marine environments: A review of recent evidence on the effects of enrichment. Limnology and Oceanography, 1988, 33(4) : 796-822.

[ 2 ] Xu H, Paerl HW, Qin BQ et al. Nitrogen and phosphorus inputs control phytoplankton growth in eutrophic Lake Taihu, China. Limnology and Oceanography, 2010, 55(1) : 420-432.

[ 3 ] Berman T, Bronk DA. Dissolved organic nitrogen: a dynamic participant in aquatic ecosystems. Aquatic Microbial Ecolo$g y, 2003, \mathbf{3 1}(3): 279-305$.

[ 4 ] Berman T. Dissolved organic nitrogen utilization by an Aphanizomenon bloom in Lake Kinneret. Journal of Plankton Research, $1997, \mathbf{1 9}(5)$ : 577-586.

[ 5 ] Berman T. Urea in the waters of Lake Kinneret (Sea of Galilee). Limnology and Oceanography, 1974, 19(6) : 977-980.

[6] $\mathrm{Gu} \mathrm{BH}$, Alexander V. Dissolved nitrogen uptake by a cyanobacterial bloom (Anabaena flos-aquae) in a subarctic lake. Applied and Environmental Microbiology, 1993, 59(2) : 422-430.

[ 7 ] Mccarthy JJ, Wynne D, Berman T. The uptake of dissolved nitrogenous nutrients by Lake Kinneret ( Israel) Microplankton. Limnology and Oceanography, 1982, 27 (4) : 673-680.

[ 8 ] Takamura N, Iwakuma T, Yasuno M. Uptake of ${ }^{13} \mathrm{C}$ and ${ }^{15} \mathrm{~N}$ (ammonium, nitrate and urea) by Microcystis in lake Kasumigaura. Journal of Plankton Research, 1987, 9(1): 151-165.

[ 9 ] Présing M, Herodek S, Preston T et al. Nitrogen uptake and the importance of internal nitrogen loading in Lake Balaton. Freshwater Biology, 2001, 46(1): 125-139.

[10] Gu BH, Karl EH, Claire LS et al. Uptake of dissolved nitrogen by phytoplankton in a eutrophic subtropical lake. Journal of Plankton Research, 1997, 19(6) : 759-770.

[11］焦念志. 海洋浮游生物氮吸收动力学及其粒级特征. 海洋与湖沼, 1995,26(2):191-198.

[12] 陈 敏,黄奕普,邱雨声. 白令海盆氮吸收速率的同位素示踪. 自然科学研究进展, 2007,17(12):1672-1684.

[13] 李清雪. 渤海湾浮游生物氮吸收动力学研究. 河北建筑科技学院学报, 2001,18(2):1-4.

[14] 秦伯强,胡维平, 陈伟民等. 太湖水环境演化过程与机理. 北京:科学出版社, 2004:1.

[15] 金相灿, 屠清瑛. 湖泊富营养化调查规范. 北京:中国环境科学出版社, 1990:317.

[16] Koroleff F. Determination of urea. In: Grasshoff K, Ehrhardt M, Kremling K, ed. Methods of seawater analysis. New York: Verlag Chemie, 1983.

[17] 黄祥飞,章祥飞. 淡水浮游生物研究方法. 北京:科学出版社, 1991:336.

[18] 胡鸿钧,魏印心. 中国淡水藻类: 系统、分类及生态. 北京:科学出版社,2006.

[19] Dugdale RC, Wilkerson FP. The use of ${ }^{15} \mathrm{~N}$ to measure nitrogen uptake in eutrophic oceans: experimental considerations. Limnology and Oceanography, 1986, 31(4) : 673-689. 
[20 ] Middelvurg JJ, Nieuwenhuize J. Nitrogen uptake by heterotrophic bacteria and phytoplankton in the nitrate-rich Thames estuary. Marine Ecology Progress Series, 2000, 203 : 13-21.

[21] Berman T, Bronk DA. Dissolved organic nitrogen: a dynamic participant in aquatic ecosystems. Aquatic Microbiology Ecology, 2003, 31: 279-305.

[22] Patricia MG, Robert M, Michael WL et al. Harmful algal blooms in the Chesapeake and Coastal Bays of Maryland, USA: comparison of 1997, 1998, and 1999 events. Estuaries, 2001, 24(6A) : 875-883.

[23] Raphael MK, Jenny QL, William PC. The potential role of anthropogenically derived nitrogen in the growth of harmful algae in California, USA. Harmful Algae, 2008, 8: 103-110.

[24] Li J, Patricia MG, Zhou MJ. Temporal and spatial variability in nitrogen uptake kinetics during harmful dinoflagellate blooms in the East China Sea. Harmful Algae, 2010, 9: 531-539.

[25] Berg GM, Balode M, Purina I et al. Plankton community composition in relation to availability and uptake of oxidized and reduced nitrogen. Aquatic Microbial Ecology, 2003, 30: 263-274.

\section{“三峡水库专辑” 征稿通知}

三峡水库是三峡大坝建成后蓄水形成的人工湖泊, 面积 $1084 \mathrm{~km}^{2}$, 库容 $393 \times 10^{8} \mathrm{~m}^{3}(175 \mathrm{~m}$ 蓄水高程 时), 是中国最大的水库. 自从 1994 年三峡工程开工,2003 年初次蓄水以来,三峡水库对长江流域乃至中国 的社会、经济、生态和环境的影响就受到了空前关注. 近 20 年来, 为保障三峡大坝充分发挥综合效益, 促进 库区和长江流域的国民经济和社会的可持续发展,我国的诸多领域学者对三峡水库以及库区作了大量的 调研,积累了丰富的资料. 近年来, 三峡水库水环境正引起越来越多的管理、研究和产业部门的关注, 同时 也引起世界的瞩目. 为加强我国水库工作者在三峡水库研究方面的交流和沟通, 推动三峡水库在生态安全 和环境效应等方面的研究和管理水平, 《湖泊科学》编辑委员会决定组织一期有关三峡水库专辑, 计划于 2012 年初出版( 第 24 卷第 2 期, 2012 年 3 月出版).

1 征稿范围:

1) 作为大型水库的水库湖沼学特征;

2) 蓄水前后生态系统要素、结构、功能的变化;

3) 水库水域、消落区、生态屏障区和库区重要支流的污染控制、环境承载力分析;

4 ) 水库水环境质量、营养状态及早期富营养化监测与评价;

5 ）三峡水库生态屏障区建设、生态安全和生态预警研究;

6) 三峡水库与长江流域水文态势及影响;

7 ) 其它与三峡水库相关的研究.

2 投稿要求

1) 投稿方式:请投稿至 jlakes@ niglas. ac. cn 或 jlakes@163.com. 投稿请注明: 三峡水库专辑.

2) 稿件格式: 参照《湖泊科学》论文格式(学报网站上提供了论文模版, 可下载; http://www. jlakes. org).

3 ) 投稿文章未在任何正式出版物上发表过,也不在其它刊物的审稿过程中,不存在一稿多投现象; 保 证投稿文章的合法性 (无抄袭、剽窃、侵权等不端行为).

4) 其它投稿须知请参阅《湖泊科学》投稿指南 (http://www. jlakes. org).

$5)$ 《湖泊科学》不收稿件审理费; 投稿作者需提交投稿声明; 录用刊发文章将收取《湖泊科学》标准版 面费; 发表之后, 将按《湖泊科学》标准支付稿酬, 并赠送样刊及单行本.

3 重要日期

截稿:2011 年 10 月 15 日; 录用通知发出:2011 年 11 月 30 日; 录用修改稿提交:2011 年 12 月 15 日; 出 版:2012 年第 2 期. 